\title{
Double-Orifice Mitral Valve with Leaflet Perforation
}

Kenji Harada, Chiyo Ichimiya, Takafumi Harada and Hiroyuki Fujinaga

Key words: double-orifice mitral valve, three-dimensional transthoracic echocardiography, perforation, mitral regurgitation

(Intern Med 56: 1745-1746, 2017)

(DOI: 10.2169/internalmedicine.56.8450)

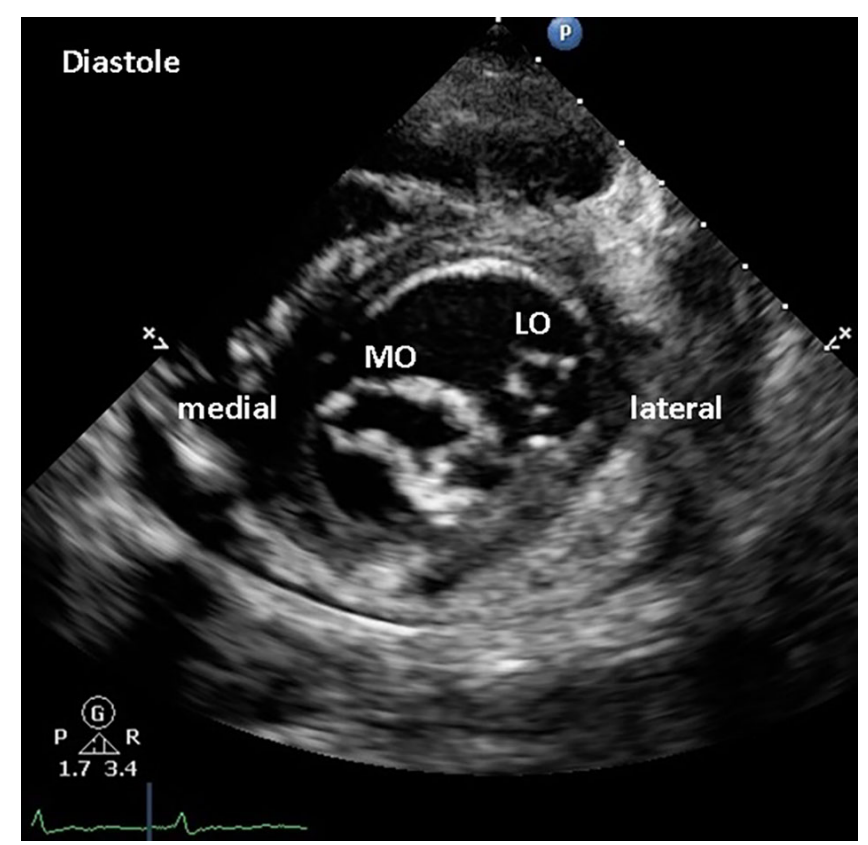

Picture 1.

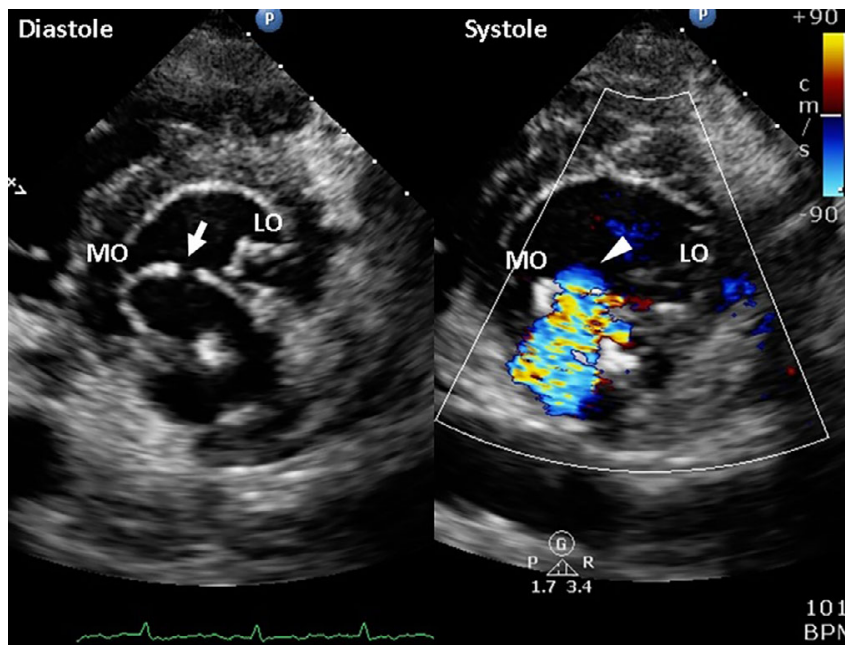

Picture 2.

Department of Cardiovascular Medicine, Tokushima Prefectural Central Hospital, Japan Received for publication October 28, 2016; Accepted for publication November 7, 2016 Correspondence to Dr. Kenji Harada, haraken40@yahoo.co.jp 


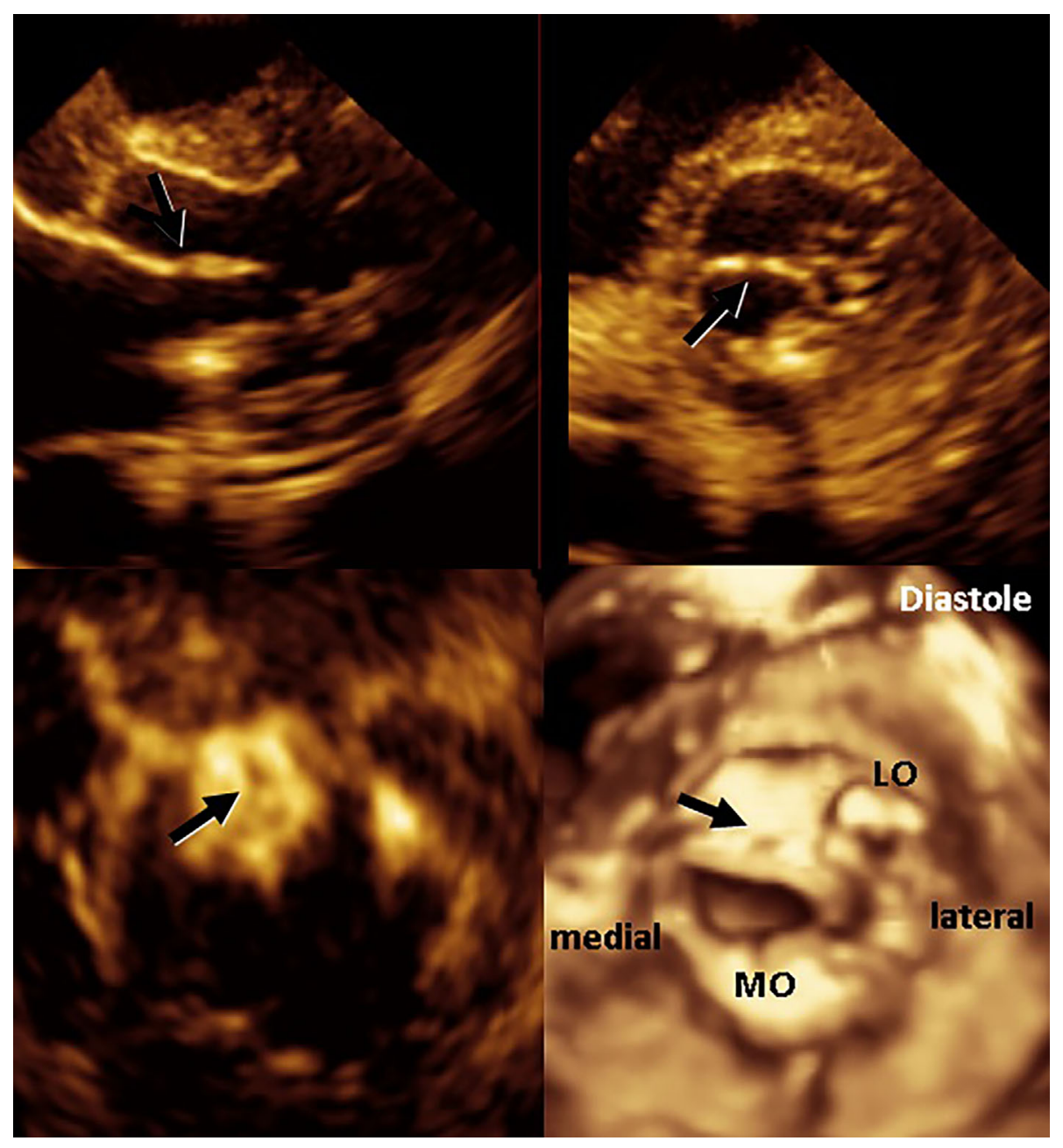

Picture 3.

An 81-year-old woman with atrial fibrillation was referred to our institution due to acute right lower limb ischemia with absent pulses. A physical examination revealed a grade2 systolic murmur at the apex. Two-dimensional transthoracic echocardiographic short-axis images showed two asymmetric orifices at two different locations (Picture 1, medial orifice: MO, and lateral orifice: LO). A hole-type double-orifice mitral valve was diagnosed based on the echocardiographic findings (1). No abnormalities were observed in the other heart valves. Color-Doppler echocardiography demonstrated severe mitral regurgitation (Picture 2, arrowhead), probably due to a small cleft or defect (Picture 2, white arrow) in the anterior leaflet tip of the medial orifice. Rather than a cleft, 3-dimensional transthoracic echocardiographic imaging from a ventricular perspective clearly showed a small, isolated perforation of $3 \mathrm{~mm}$ in di- ameter at the site (Picture 3, black arrow). However, it is unclear whether the leaflet perforation occurred due to a congenital disorder or an acquired disorder such as infective endocarditis.

The authors state that they have no Conflict of Interest (COI).

\section{Reference}

1. Trowitzsch E, Bano-Rodrigo A, Burger BM, Colan SD, Sanders SP. Two-dimensional echocardiographic findings in double orifice mitral valve. J Am Coll Cardiol 6: 383-387, 1985.

The Internal Medicine is an Open Access article distributed under the Creative Commons Attribution-NonCommercial-NoDerivatives 4.0 International License. To view the details of this license, please visit (https://creativecommons.org/licenses/ by-nc-nd/4.0/).

(C) 2017 The Japanese Society of Internal Medicine http://www.naika.or.jp/imonline/index.html 